\title{
Paracrine signaling by glial cell-derived triiodothyronine activates neuronal gene expression in the rodent brain and human cells
}

\author{
Beatriz C.G. Freitas,, ${ }^{1}$ Balázs Gereben, ${ }^{2}$ Melany Castillo, ${ }^{3}$ Imre Kalló,2 Anikó Zeöld, ${ }^{2}$ \\ Péter Egri, ${ }^{2}$ Zsolt Liposits, ${ }^{2}$ Ann Marie Zavacki, ${ }^{4}$ Rui M.B. Maciel, ${ }^{1}$ Sungro Jo, ${ }^{3}$ \\ Praful Singru, ${ }^{5}$ Edith Sanchez, 5 Ronald M. Lechan, 5,6 and Antonio C. Bianco ${ }^{3}$
1 Laboratory of Molecular Endocrinology, Division of Endocrinology, Department of Medicine, Federal University of São Paulo, São Paulo SP, Brazil. ${ }^{2}$ Laboratory of Endocrine Neurobiology, Institute of Experimental Medicine, Hungarian Academy of Sciences, Budapest, Hungary. ${ }^{3}$ Division of Endocrinology, Diabetes and Metabolism, University of Miami Miller School of Medicine, Miami, Florida, USA.
4Thyroid Section, Division of Endocrinology, Diabetes, and Hypertension, Brigham and Women's Hospital, Boston, Massachusetts, USA. ${ }^{5}$ Tupper Research Institute, Department of Medicine, Division of Endocrinology, Diabetes and Metabolism, Tufts Medical Center, Boston, Massachusetts, USA. ${ }^{6}$ Department of Neuroscience, Tufts University School of Medicine, Boston, Massachusetts, USA.

\begin{abstract}
Hypothyroidism in humans is characterized by severe neurological consequences that are often irreversible, highlighting the critical role of thyroid hormone (TH) in the brain. Despite this, not much is known about the signaling pathways that control TH action in the brain. What is known is that the prohormone thyroxine (T4) is converted to the active hormone triiodothyronine (T3) by type 2 deiodinase (D2) and that this occurs in astrocytes, while $\mathrm{TH}$ receptors and type 3 deiodinase (D3), which inactivates $\mathrm{T} 3$, are found in adjacent neurons. Here, we modeled TH action in the brain using an in vitro coculture system of D2-expressing $\mathrm{H} 4$ human glioma cells and D3-expressing SK-N-AS human neuroblastoma cells. We found that glial cell D2 activity resulted in increased $\mathrm{T} 3$ production, which acted in a paracrine fashion to induce T3-responsive genes, including ectonucleotide pyrophosphatase/phosphodiesterase 2 (ENPP2), in the cocultured neurons. D3 activity in the neurons modulated these effects. Furthermore, this paracrine pathway was regulated by signals such as hypoxia, hedgehog signaling, and LPS-induced inflammation, as evidenced both in the in vitro coculture system and in in vivo rat models of brain ischemia and mouse models of inflammation. This study therefore presents what we believe to be the first direct evidence for a paracrine loop linking glial D2 activity to TH receptors in neurons, thereby identifying deiodinases as potential control points for the regulation of TH signaling in the brain during health and disease.
\end{abstract}

\section{Introduction}

One of the most devastating aspects of neonatal hypothyroidism is severe neurologic impairment and mental retardation, frequently associated with abnormal facies, deaf mutism, and motor spasticity $(1,2)$. These features are by and large irreversible, and a worldwide network of neonatal screening was put in place several decades ago to identify and treat the newborns with this condition. The adult brain is also sensitive to thyroid hormone (TH). Hypothyroid patients are frequently lethargic, have poor motor coordination, memory impairment, and a tendency toward depression and mood disorders. In turn, hyperthyroidism is associated with irritability, anxiety, and mood swings (3), and the efficacy of antidepressive agents is potentiated when associated with $\mathrm{TH}$ administration.

While these syndromes illustrate a critical role played by $\mathrm{TH}$ in brain, not much is known about the signaling pathways that control TH action in this organ. In contrast with the majority of tissues, most TH in the brain is produced locally through activa-

Authorship note: Beatriz C.G. Freitas and Balázs Gereben contributed equally to this work.

Conflict of interest: The authors have declared that no conflict of interest exists. Citation for this article: J Clin Invest. 2010;120(6):2206-2217. doi:10.1172/JCI41977. tion of thyroxine (T4) to 3,5,3'-triiodothyronine (T3) via the action of the type 2 deiodinase (D2) (4). This has been studied directly through dual-labeling techniques and recently confirmed with the observation that mice with targeted disruption of the DIO2 gene exhibit half as much T3 in their brains as WT littermates (5). Thus, it is widely accepted that D2 expression in discrete areas of the brain increases TH signaling, a mechanism that has been linked to important brain functions such as cochlear development, the thyrotropin-releasing hormone/thyroid-stimulating hormone (TRH/TSH) feedback mechanism, and seasonal breeding in birds $(6,7)$. At the same time, the TH-inactivating type 3 deiodinase (D3) pathway is also active in discrete areas of the brain, dampening TH action. Not surprisingly, the D2 and D3 pathways are inversely synchronized in a spatial and temporal fashion. Thus, it is assumed that the balance of these 2 pathways, i.e., D2 versus $\mathrm{D} 3$, and the less significant contribution of plasma T3, determine critical brain processes such as myelination, neuronal migration, glial differentiation, and neurogenesis $(1,8,9)$.

Neurons express TH receptors (TRs) and are presumably the major target of T3 in the brain, but D2 is expressed in astrocytes, not neurons. This poses an anatomical question: does T3 generated in astrocytes reach TRs in neurons $(2,10,11)$ ? Furthermore, does the expression of D3 in the neurons limit this paracrine path- 
way? Such a paracrine mechanism became more plausible with the discovery of active $\mathrm{TH}$ transport into neurons via transporters such as monocarboxylate TH transporter-8 (MCT8): mutations in MCT8 explain the molecular basis for the Allan-Herndon-Dudley syndrome (AHDS), a rare X-linked disorder characterized by neurological abnormalities including global developmental delay, central hypotonia, rotatory nystagmus, impaired hearing, and spasticity $(12,13)$. Another line of evidence supporting the concept of paracrine $\mathrm{TH}$ transport in the brain stems from studies of TH metabolism in the hypothalamus, where D2 is expressed in specialized glial cells located in the floor and infralateral wall of the third ventricle in the mediobasal hypothalamus $(\mathrm{MBH})$ called tanycytes $(14,15)$. It has been suggested that $\mathrm{T} 3$ generation via D2 in tanycytes could affect gene expression in TRH neurons, located in the paraventricular nucleus (PVN), thus explaining why T4 is critical in the negative feedback of TRH (16). At the same time, upregulation of D2 in tanycytes has been demonstrated in a rodent model for nonthyroidal illness and fasting, suggesting that a relative local increase in $\mathrm{TH}$ action mediates the central hypothyroidism frequently observed under these circumstances (17-19). In the Japanese quail, the expression of D2 in the MBH is induced by light. Intracerebroventricular administration of $\mathrm{T} 3$ mimics the photoperiodic response, whereas the D2 inhibitor iopanoic acid prevents gonadal growth, indicating that light-induced D2 expression in the medial basal hypothalamus (MBH) may be involved in the photoperiodic response of gonads in Japanese quail (7).

If this glial-D2/neuronal TR connection indeed exists, it could have the advantage of allowing for a much more sophisticated regulation of TH action in the brain, with control of glial or neuronal deiodination being a control point. A number of signaling pathways that have recently been established to be relevant for deiodinases could be operant in the brain, for example, HIF- $1 \alpha$ activation of D3 in hypoxic tissue (20) and hedgehog protein family-mediated inactivation of D2 and activation of D3 $(21,22)$.

Direct evidence of a deiodinase-mediated transcriptional T3 footprint in neurons has not been available. Here we modeled this pathway in vitro by coculturing D2-expressing $\mathrm{H} 4$ glioma cells with neuronal cells that express D3, SK-N-AS. Using this system, we found that glial cell-generated T3 (via D2 activity) was able to act in a paracrine fashion to induce the expression of T3-responsive genes in cocultured neurons, in spite of the presence of D3 activity. Furthermore, we found that the system is regulated by signals including hypoxia, hedgehog proteins, and LPS-induced inflammation. In vivo studies using ischemia and LPS further validate the relevance of these findings. To our knowledge, these data represent the first direct evidence for a paracrine loop linking D2 in glial cells to TRs in neurons, identifying deiodinases as control points for the regulation of $\mathrm{TH}$ signaling in the brain during health and disease.

\section{Results}

$\mathrm{H} 4$ and SK-N-AS cells mimic pattern of deiodinase expression found in vivo in the brain. In order to develop an in vitro model of TH metabolism and action in the brain, we first sought to identify suitable cell lines that would mimic the pattern of deiodinase expression in the brain, namely D2 expression in glial cells (14) and D3 in neurons (23). To that effect, glial-restricted precursor cells were differentiated in the presence of T3, PDGF-el, bFGF, or FCS (24), but D2 expression could not be induced in these cells (data not shown). At the same time, the screening of several glioma and microglia cell lines identified the human $\mathrm{H} 4$ glioma cells (Figure 1A) that exhibit substantial D2 activity but not type 1 deiodinase (D1) or D3 (Figure $1 \mathrm{~B}$ ). Just as in primary astrocytes (data not shown), H4 cells also express other key components of TH transport (monocarboxylic acid transporter 8 [MCT8], MCT10, and solute carrier organic anion transporter 1c1 [SLCO1C1; also known as OATP14]) and action (TR $\alpha, T R \beta$, neurogranin [NRGN; also known as RC3], and ectonucleotide pyrophosphatase/phosphodiesterase 2 [ENPP2]) in the brain (Figure 1C). As part of this model, we chose to use the SK-N-AS neuroblastoma cell line, which has D3 activity as previously characterized (Figure 1, A and B) (20). The TH transporters MCT8 and MCT10 were found to be expressed similarly in both cell lines, whereas the expression of OATP14 transporter tended to be higher in the neuroblastoma cells (Figure 1C).

Subsequently, we tested to determine whether these cell lines are responsive to $\mathrm{T} 3$ by incubating both lines in media containing charcoal-stripped serum or $100 \mathrm{nM} \mathrm{T3}$ (Figure 1D). We looked at 2 previously characterized T3-responsive genes in the brain, i.e., $R C 3$ and ENPP2 (2), having found that only SK-N-AS cells consistently respond to $\mathrm{T} 3$ in a concentration- and time-dependent fashion, increasing ENPP2 expression to a maximum of approximately 5 -fold (Figure 1, D-F). In contrast, glial cells did not respond to $\mathrm{T} 3$ at all when these same genes were tested (Figure 1, D-F). As uncoupling protein 2 (UCP2) gene expression did not change with the addition of T3 in the media of either cell type (Figure 1D), this gene was subsequently used as control.

Coculture of neuronal and glial cells is required for sensitivity to T4. To test the hypothesis that glial-derived T3 acts in neuronal cells, we took advantage of an in vitro setup designed for coculture of cells in 2 adjacent compartments that are bathed with the same culture media (Transwell System; Figure 1E). Using this setup, we first incubated both cell types with T3, having found that ENPP2 gene expression is stimulated in SK-N-AS cells regardless of whether these cells are cultured alone or with $\mathrm{H} 4$ cells; as always, the latter did not respond to exposure to T3 (Figure 1, F and G). In the next set of experiments, we chose to incubate all cells with $\mathrm{T} 4$ in media containing $0.1 \%$ BSA (instead of FBS), so that the free concentration of T4 could be defined as described previously (25). Under these conditions, $\mathrm{H} 4$ and/or SK-N-AS cells were exposed to $20 \mathrm{pM}$ free T4 (similar to free T4 concentration in human serum) for 48 hours. While approximately 2 -fold induction of ENPP2 gene expression was observed in SK-N-AS cells grown alone, coincubation with $\mathrm{H} 4$ cells magnified the T4-induced ENPP2 gene expression by approximately 7 -fold (Figure $2 \mathrm{~A}$ ). The effect of T4 on ENPP2 gene expression followed a dose-response pattern, with proportional increments observed in the range between 0 and $48 \mathrm{pM}$ (data not shown). In contrast, cell coincubation did not affect ENPP2 gene expression in SK-N-AS cells when T4 was not added to the media, and UCP2 gene expression remained stable throughout the experiment (Figure 2A). To determine whether cell coincubation could be affecting the fractional conversion of T4 to T3, and hence $\mathrm{T} 3$ production, the latter was monitored by periodic sampling of the media followed by separation and quantification of iodothyronines by UPLC as described (26). The conversion of T4 to $\mathrm{T} 3$ increased steadily only when the $\mathrm{H} 4$ cells were used, and this was not affected by coincubation with SK-N-AS cells (Figure 2B). The complete analysis of TH metabolism using different radioactive substrates confirmed that $\mathrm{H} 4$ cells metabolize T4 into T3 and iodide via D2 (Figure 2C), SK-N-AS cells further metabolize T3 into T2 and T1 via D3 (Figure 2D), and the coculture of $\mathrm{H} 4$ and SK-N-AS produces T3 and its expected metabolites (Figure 2E). 
A

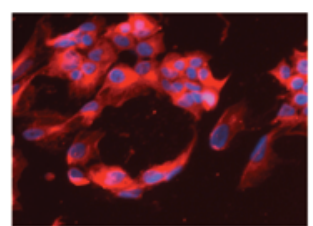

SK-N-AS

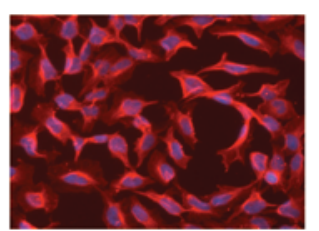

$\mathrm{H} 4$

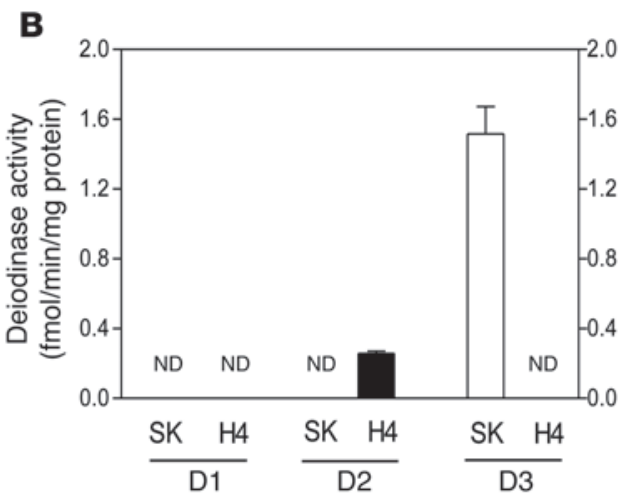

C

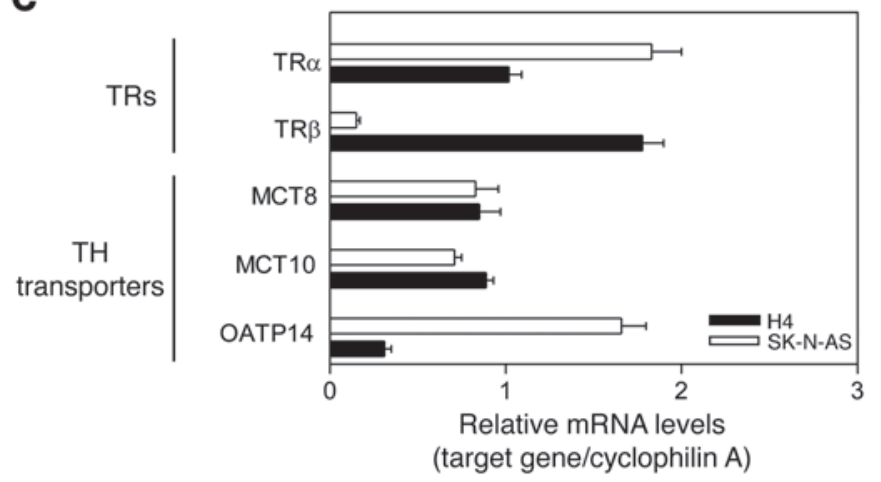

E
D

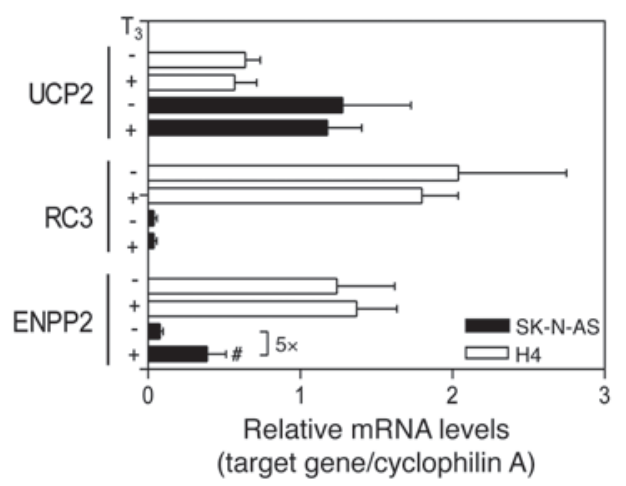

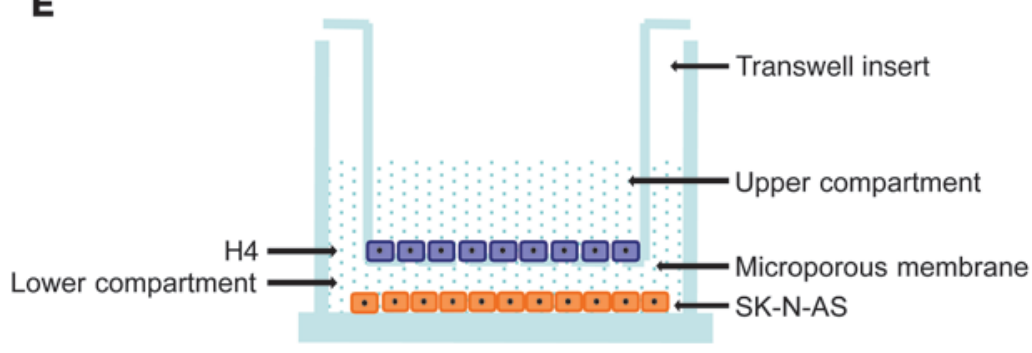

F

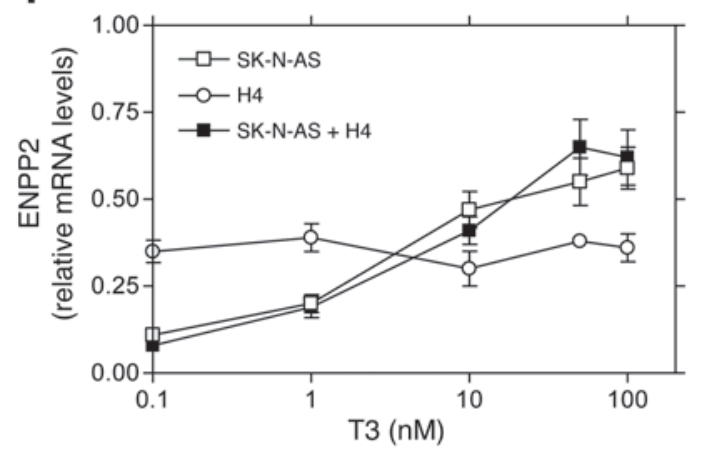

G

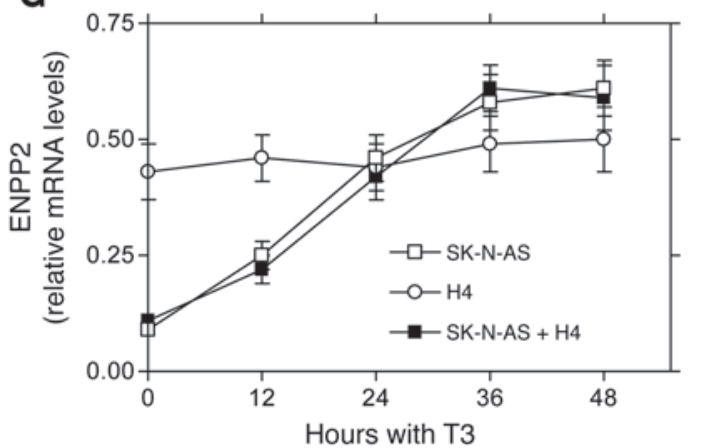

Figure 1

TH signaling in neuronal (SK-N-AS) and glial (H4) cell lines. (A) Immunocytochemistry of SK-N-AS and H4 probed with $\alpha$-tubulin and stained with DAPI. Original magnification, $\times 20$. (B) Endogenous deiodinase activity in $\mathrm{H} 4$ and SK-N-AS (SK) cell lines. nd, not detectable. (C) RNA expression pattern of genes involved in TH metabolism and action as determined by quantitative RT-PCR in H4 and SK-N-AS cell lines. (D) Responsiveness of putative T3-target genes (UCP2, RC3, and ENPP2) in H4 and SK-N-AS cell lines treated with media containing charcoal-stripped serum or $100 \mathrm{nM}$ T3 for 48 hours as indicated. 5x indicates 5-fold induction of expression. (E) Schematic representation of the Transwell System in which an insert is placed on a 6-well plate and cells $(\mathrm{H} 4)$ are seeded inside the insert; SK-N-AS cells are seeded at the bottom of the 6-well plate. After cells are seeded, both cell types are kept separated overnight and then placed together in the same multiwell plate as indicated. (F) Dose responsiveness of ENPP2 gene to T3 in H4 and SK-N-AS cell lines incubated alone as in D or coincubated in the Transwell system for 48 hours as indicated. (G) Same as in F, except that this is a time-responsiveness to T3. In all experiments, values are mean \pm SEM of 5-9 independent wells; ${ }^{*} P<0.01$ versus control. 
A

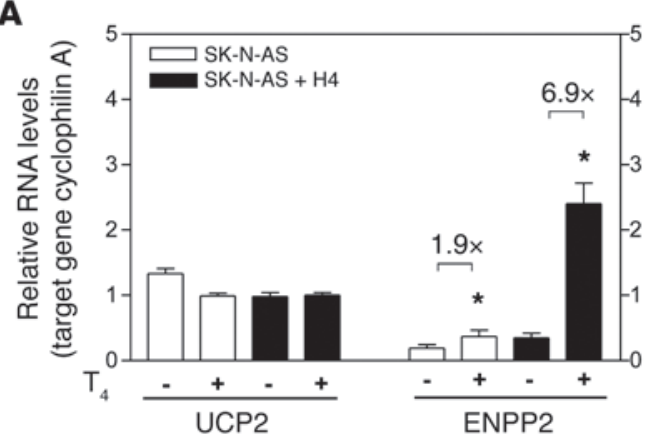

C

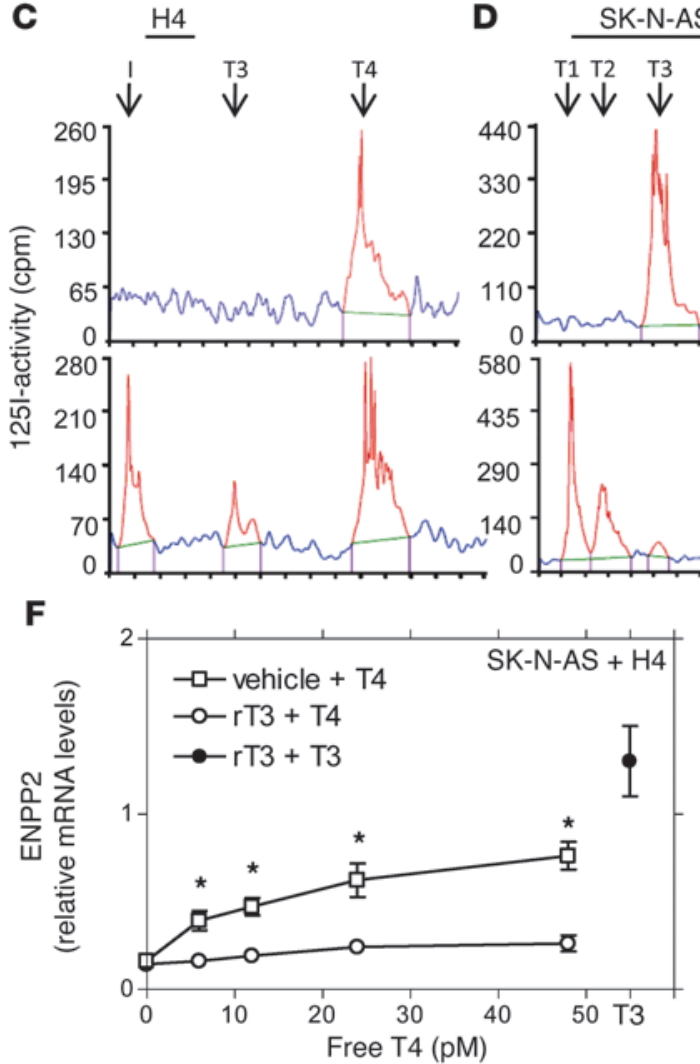

B

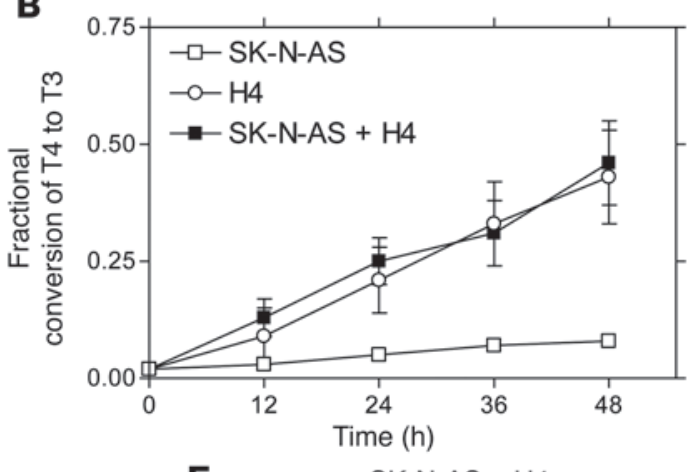

E
$\mathrm{Oh}$

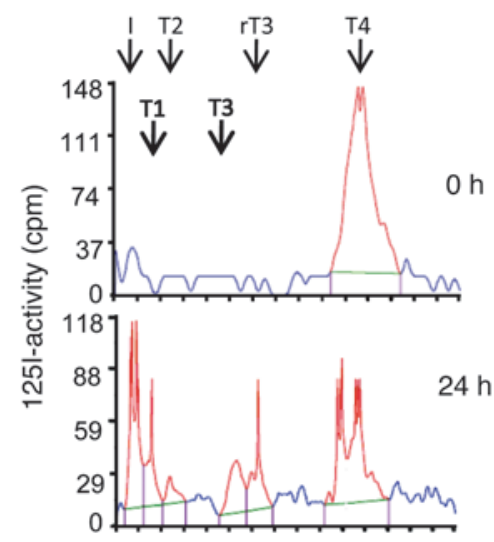

G

$24 \mathrm{~h}$

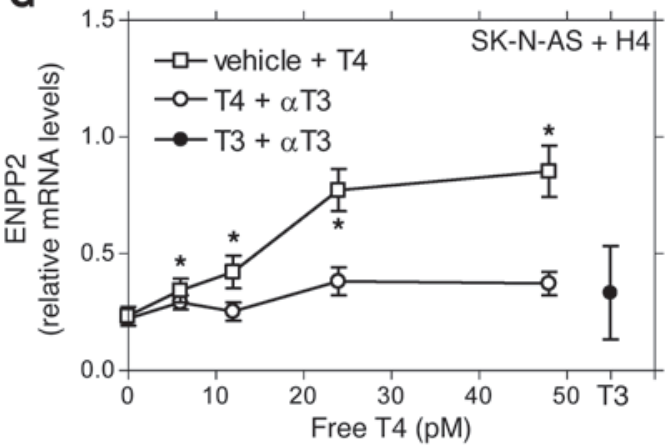

Figure 2

$\mathrm{H} 4$ astrocyte cells activate T4 into T3 and establish a mRNA footprint in neuronal SK-N-AS cells. (A) Effects of T4 addition on ENPP2 or UCP2 gene expression in cultures of SK-N-AS or cocultures of SK-N-AS and H4 cells as indicated. Cells were cultured as in legend to Figure 1 and treated with 20 pM T4 (free fraction) for 48 hours. (B) Fractional conversion of T4 to T3 as measured after addition of $125 \mathrm{I}-\mathrm{T} 4$ and determination of outer ring deiodination via measurement of free 125I. Media samples were collected at the indicated times. (C) Chromatograms of $\mathrm{H} 4$ cell medium at the indicated times after addition of 125I-T4. Typical peaks of 125-T3 and $125 \mathrm{I}$ are shown after 24 hours. (D) Same as in C, except that 125I-T3 was added to cultures of SK-N-AS cells and 125I-T2 and 125I-T1 peaks are visualized. (E) Same as in C, except that 125I-T4 was added to $\mathrm{H} 4$ and SK-N-AS cocultures and the indicated peaks are visualized. (F) Same as in A, except that different concentrations of free T4 were used and $20 \mathrm{nM} \mathrm{rT3}$ was added at the beginning of incubation as indicated. T3 indicates that $100 \mathrm{nM}$ T3 was added at the beginning of incubation. (G) Same as in $\mathbf{F}$, except that $\alpha-\mathrm{T} 3$ antiserum was added at time zero as indicated. In all experiments, values are mean \pm SEM of $5-9$ independent wells; ${ }^{\star} P<0.01$ versus control.

To verify that T4-induced ENPP2 gene expression in SK-N-AS cells is due to D2-mediated T3 production in H4 cells, we repeated

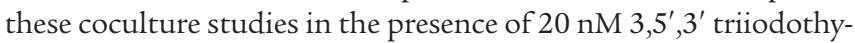
ronine (rT3), an inert iodothyronine that competitively inhibits D2 (27). While the incubation with increasing concentrations of T4 progressively increased ENPP2 gene expression in SK-A-AS cells, the same was not observed when rT3 was added to the media (Fig- ure $2 \mathrm{~F})$. As a control, rT3 did not interfere with the ENPP2 induction when $20 \mathrm{nM}$ T3 was added to the media (Figure 2F). Greater than $95 \%$ inhibition of D2 was verified at the end of the incubation period by assaying D2 activity in cell sonicates (data not shown). Next, to prove that T3 is the mediator of ENPP2 gene expression by $\mathrm{T} 4$, we repeated these studies in the presence of a high-affinity $\alpha-\mathrm{T} 3$ rabbit antiserum, previously shown to immunoneutralize T3 


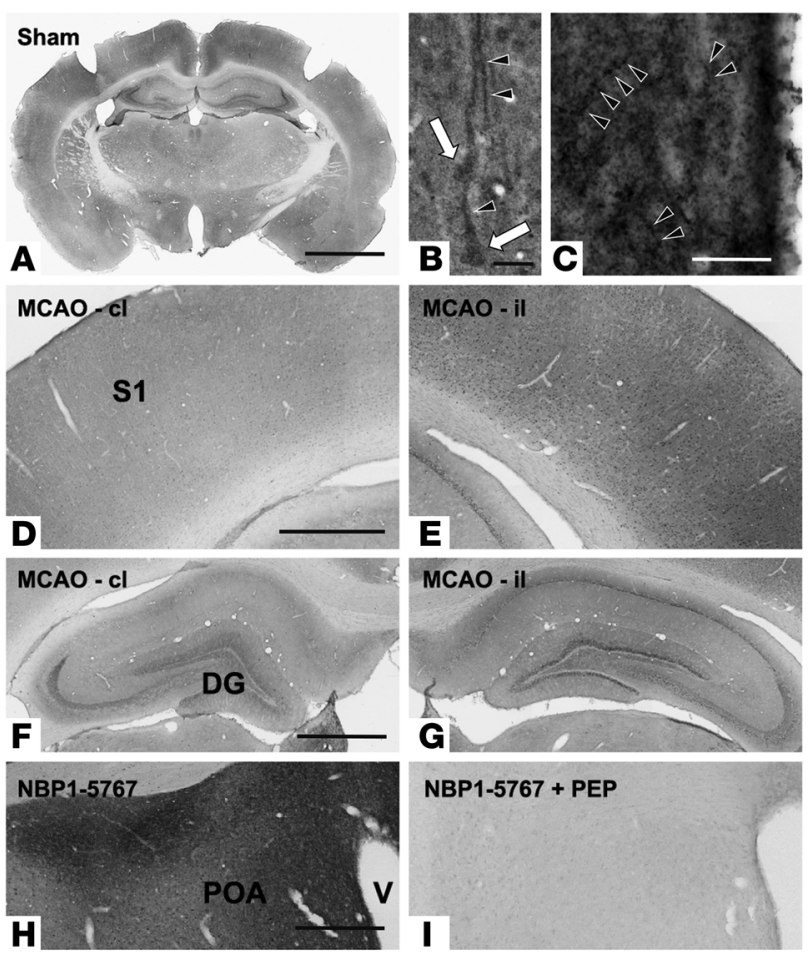

in cell media (26). Remarkably, addition of the $\alpha$-T3 antiserum significantly blunted the ENPP2 response to T4 (Figure $2 \mathrm{G}$ ), without affecting the fractional conversion of T4 to T3 (data not shown).

Hypoxia and hedgehog pathway decrease the astrocyte-mediated neuronal transcriptional T3 footprint in a model of brain stroke. Once we determined that $\mathrm{T} 3$ production by glial cells (H4) defines a specific transcriptional footprint in neuronal cells (SK-N-AS), we sought to verify whether programmed changes in deiodinase activity that were triggered by physiologically and/or pathophysiologically relevant pathways in the brain could affect this mechanism. A stroke model was tested, given that ischemia and hypoxia induce D3 expression via an HIF- $1 \alpha$-mediated mechanism in postinfarction myocardium and during hypertrophic cardiac insufficiency (20). To model such a system in vivo, we first analyzed the pattern of D3 expression in the brain. In sham-operated animals, strong D3 immunoreactivity (IR) was detected in the preoptic area, bed nucleus of the stria terminalis, and hypothalamus, while moderate IR was observed in the cortex and hippocampus, but rather low IR was present in the thalamus (Figure 3A). In concordance with previous in situ hybridization studies showing strong signals of D3 mRNA in neuron-rich layers of the cortex and hippocampus (15), the D3 IR appeared in the perikaryon and the apical dendrites of the pyramidal cells (Figure 3B) and immunoreactive axons emanating from the strongly immunolabeled areas of the preoptic area and the hypothalamus were also visible (Figure 3C). Occlusion of the middle cerebral artery $(\mathrm{MCAO})$ resulted in dramatic induction of D3 IR in neurons in the ipsilateral somatosensory cortex (Figure $3 \mathrm{E}$ ) and hippocampus (Figure 3G).

As these in vivo data confirm the importance of D3 induction in ischemic neuronal tissue, we took advantage of the cell coculture system characterized here to study the astrocyte-mediated transcriptional T3 footprint under hypoxic conditions, in a chamber containing $2 \%$ oxygen. Hypoxia was documented by the progressive

\section{Figure 3}

Hypoxia induces D3 in the brain and decreases TH signaling. D3 IR using the NBP1-5767 $\alpha$-D3 antiserum in coronal brain sections of male rat stroke model: (A-C) sham operated; (D-I) unilateral MCAO for 1 hour. (A) Low-power micrograph of a coronal brain section (bregma, $-3.3 \mathrm{~mm}$ ) shows widespread distribution of D3 IR in sham. The intensity of D3 staining exhibits regional variations; in the cerebral cortex and hippocampus of sham-operated controls, the IR is moderate and localized primarily to the apical dendrite (arrowheads) and the perikaryon (arrows) of pyramidal cells (B), whereas it is intense in the axons (arrowheads) and cell bodies of the hypothalamic preoptic area (C). (D-E) Ischemia resulted in an increased D3 IR on the ipsilateral side (MCAO-il) compared with the control contralateral side (MCAO-cl) of the occlusion shown for both the primary somatosensory cortex (E versus $\mathbf{D}$ ) and the hippocampus ( $\mathbf{G}$ versus $\mathbf{F})$. (H-I) Preincubation of the primary antibody with the peptide antigen (PEP) used for immunization resulted in complete loss of immunostaining demonstrated in neighboring hypothalamic sections. Scale bars: $3 \mathrm{~mm}$ (A); $50 \mu \mathrm{m}$ (B); $100 \mu \mathrm{m}$ (C); $1 \mathrm{~mm}$ (D-I). DG, dentate gyrus; POA, preoptic area; S1, primary somatosensory cortex; $\mathrm{V}$, third ventricle.

increase in PFK mRNA levels in both cell types (Figure 4A). Under these conditions, there was an approximately 6-fold increase in D3 activity in SK-N-AS cells and a parallel approximately 2 -fold increase in D2 activity in the $\mathrm{H} 4$ cells (Figure 4B). Along with these changes in deiodinase expression, the T4-induced EPPN2 gene expression in neurons was decreased by approximately $50 \%$, while hypoxia alone did not affect basal ENPP2 mRNA levels (Figure 5C) or UCP2 mRNA (data not shown). D3 expression is upregulated by HIF-1 $\alpha$ and thus we also used the iron chelator desferrioxamine (DFX), a hypoxia mimetic that inhibits HIF ubiquitination and leads to its accumulation even under normoxic conditions. Remarkably, exposing the coculture system to $100 \mu \mathrm{M}$ DFX elicited results very similar to hypoxia, i.e., a decrease in TH signaling in SK-N-AS cells, confirming the involvement of HIF-1 $\alpha$ in this pathway (Figure 4, D-F).

In the brain, sonic hedgehog (Shh) protein is expressed in neurons and has been implicated in injury remodeling caused by stroke and hypoxia (28). In the setting of our coincubation system, addition of $4 \mu \mathrm{g} / \mathrm{ml}$ Shh to the coincubation media rapidly increased patched (PTC) expression in both cell types, but mainly in SK-N-AS cells, indicating that the Shh signaling pathway is active in these cells (Figure 5A). Addition of Shh dramatically increased D3 activity in SK-N-AS cells, while there was progressive loss of D2 activity in the glial cells (Figure 5B). More importantly, while addition of T4 progressively induced neuronal ENPP2 gene expression, the Shh-induced changes in deiodinase activity blunted the effect of T4 without affecting basal ENPP2 gene expression (Figure 5C) or UCP2 expression (Figure 5D). In a reverse strategy, we used cyclopamine, an antagonist of Shh, which progressively decreased PTC mRNA levels (Figure 5E) and D3 activity and increased D2 activity by approximately 3.5 -fold (Figure 5F). Remarkably, cyclopamine doubled the effect of T4 on ENNP2 gene expression, increasing it from approximately 7 - to 15 -fold (Figure 5G), whereas only minor changes in UCP2 expression were observed (Figure $5 \mathrm{H}$ ).

LPS-induced inflammation amplifies the astrocyte-mediated neuronal transcriptional T3 footprint in a model of central bypothyroidism. At the same time, we looked at physiological and/or pathophysiological models in which changes in deiodinase expression could increase TH signaling. For example, it is known that in rats, the i.p. administration of LPS induces D2 expression in tanycytes that is associated with suppression of TRH expression and central hypothyroidism, 

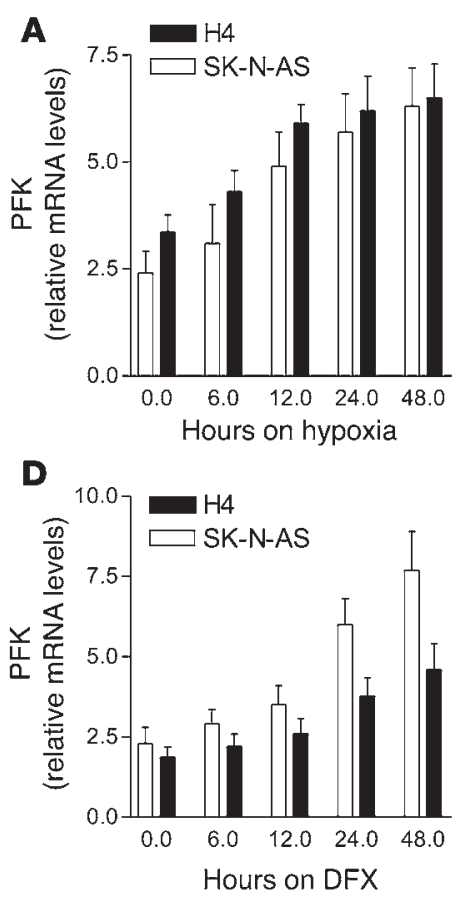

B
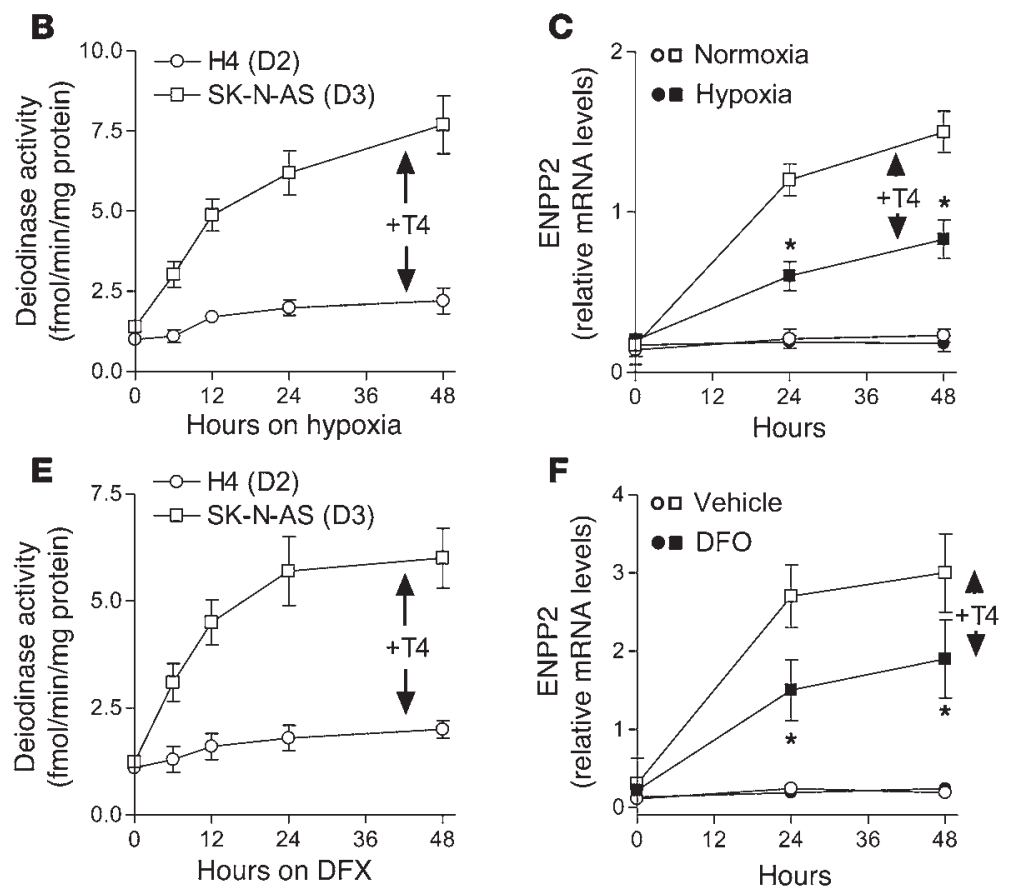

\section{Figure 4}

Hypoxia decreases astrocyte-mediated thyroid hormone signaling in neuronal SK-N-AS cells. (A) The coculture system described in Figure 2 was placed in a hypoxia chamber $\left(1 \% \mathrm{O}_{2}\right)$ for the indicated times in the presence of $20 \mathrm{pM} \mathrm{T4}$ (free fraction). Cells were harvested at the indicated times and processed for deiodinase activity or quantitative RT-PCR. PFK, phosphofructokinase. (B) Time course of D2 and D3 activities after hypoxia was initiated. (C) ENPP2 mRNA levels in SK-N-AS cells at the indicated time points. (D-F) Same as in A-C, except that cells were treated with DFX for the indicated times. Values are mean \pm SEM of $6-9$ independent wells; ${ }^{*} P<0.01$ versus control.

mimicking the situation found in nonthyroidal illness (18). This would indicate that an increase in D2 activity in the tanycytes augments local T3 concentration, negatively regulating TRH expression in discrete neurons of the hypothalamic PVN. To determine the extent to which D2 is involved in such a mechanism, we first analyzed PVN TRH mRNA levels in WT and D2-KO mice 12-24 hours after the systemic administration of LPS (Figure 6). While an expected reduction of over $50 \%$ in TRH mRNA was observed in the WT animals following LPS (Figure 6, A, B, and E), the D2-KO animals failed to reduce TRH mRNA levels (Figure 6, C-E). This confirms that $\mathrm{D} 2$ is a critical component of this pathway.

Currently there are no tanycyte (cell) models that provide sufficiently high cell purity for studies such as these. Thus, to model the interrelationship between these cells and TRH-expressing neurons in the PVN, we coincubated neuronal SK-N-AS cells with $\mathrm{H} 4$ glioma cells, which share a similar glial origin with tanycytes. The ENPP2 responsiveness to T4 was then tested after the addition of LPS. To ensure that the timing and concentration dependence of the LPS effects was compatible with the cell model developed in the present studies, we used HEK-TLR4MD2-ELAM cells, which have functional LPS-NF-KB signaling via stable expression of the TLR4 receptor and an NF-KB-responsive Luciferase reporter (29). In these cells, addition of $1 \mu \mathrm{g} / \mathrm{ml}$ LPS to the media resulted in several-fold activation of the Luc reporter gene (Figure 6F) by 6 hours. When used at the same concentrations in the coincubation cell system, LPS triggered major changes in deiodinase expression, as documented by the approximately 3-fold increase in D2 mRNA/activity and approximately $30 \%$ decrease in D3 mRNA and activity (Figure 6, G-H). Conse- quently, there was a dramatic increase in T4-mediated induction of neuronal ENPP2 gene expression (Figure 6I), whereas UCP2 mRNA remained largely unaffected (Figure 6J).

\section{Discussion}

These present studies give exciting insights, which we believe are new, into how deiodinases regulate $\mathrm{TH}$ action in the brain during health or disease, providing direct evidence for a unique paradigm of TH action. Three steps characterize this paracrine mechanism: first, the prohormone T4 is activated in glial cells (astrocytes and tanycytes) via $\mathrm{D} 2$; next, the resultant $\mathrm{T} 3$ exits the glial compartment and enters adjacent neurons; and finally, the T3 establishes a transcriptional footprint via binding to neuronal TRs (Figure 7). The physiologic implications are considerable, since the generation of $\mathrm{T} 3$ and its translocation are both potential control points for $\mathrm{TH}$ signaling in the brain. It is remarkable that the magnitude of the glial D2-mediated T3 footprint in neurons is not constant; on the contrary, it can be modulated by coordinated changes in D2 and D3 activities, amplifying or minimizing the $\mathrm{TH}$ signaling depending on whether the changes favor $\mathrm{TH}$ activation (via D2) or inactivation (via D3) via the actions of key developmental and/or metabolic molecules such as hedgehog proteins, HIF-1 $\alpha$, and LPS.

That deiodinases in glial cells and neurons can affect TH signaling was proposed based on their anatomical distribution and on the role that deiodinases play in other cell systems such as brown adipose tissue and pituitary gland (2). The present findings provide a mechanistic explanation for how this happens, unequivocally demonstrating that enough D2-generated T3 acts in a paracrine fashion, establishing a transcriptional footprint in neuronal 
A

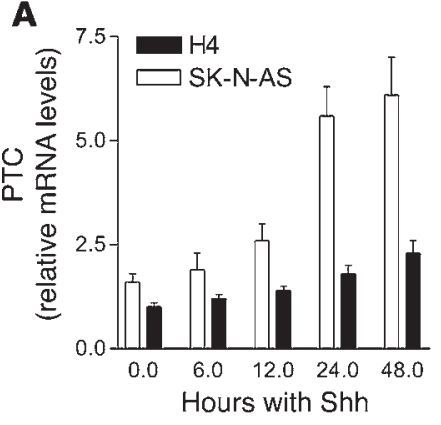

D

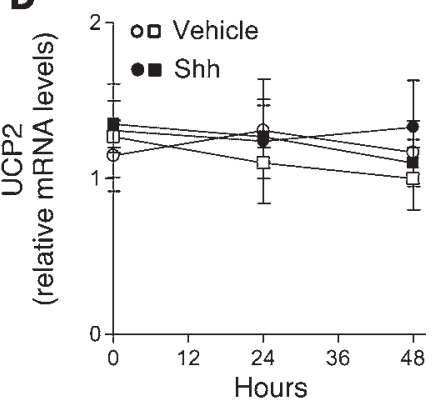

G

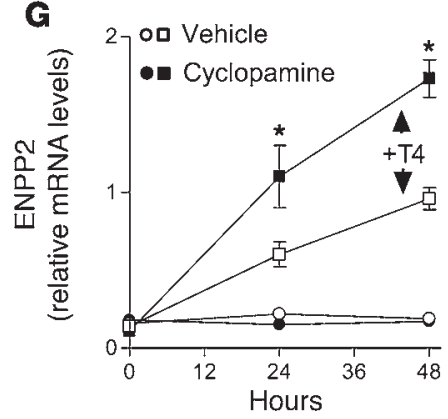

B

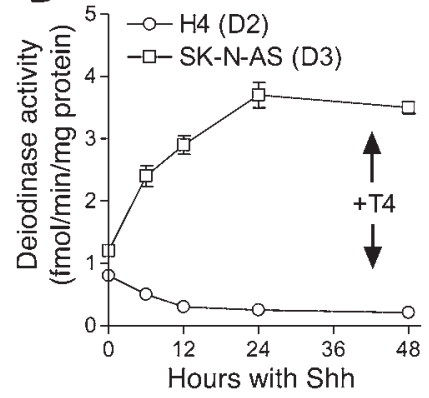

E

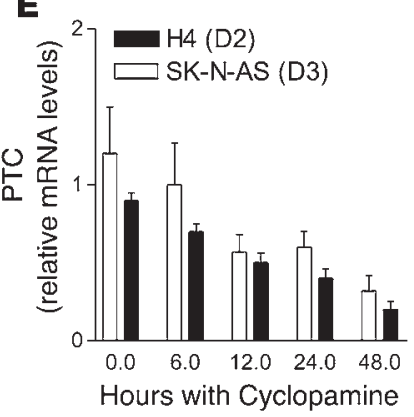

H

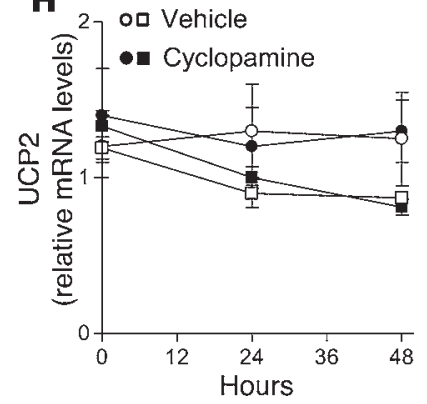

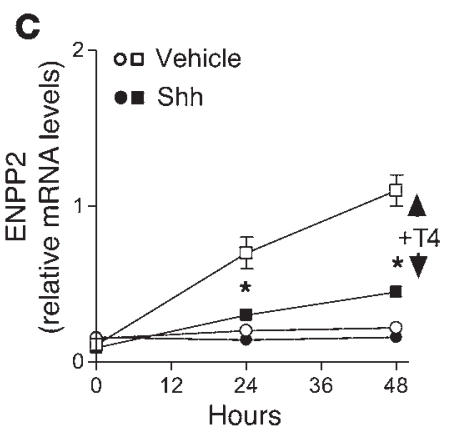

F

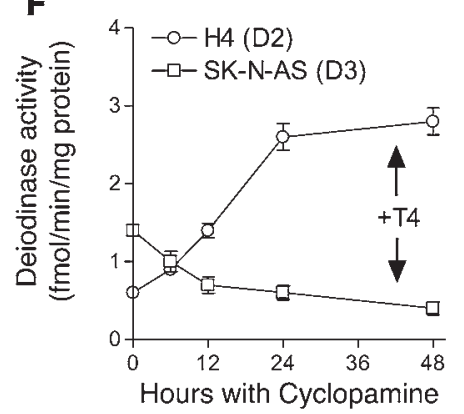

\section{Figure 5}

Shh signaling limits the $\mathrm{H} 4$ astrocyte-mediated mRNA footprint in neuronal SK-N-AS cells. The coculture system described in Figure 2 was exposed to Shh for the indicated times in the presence of 20 pM T4 (free fraction). Cells were harvested at the indicated times and processed for deiodinase activity or quantitative RT-PCR. (A) Time course of PTC expression after addition of Shh. (B) Time course of D2 and D3 activities after addition of Shh. (C) ENPP2 mRNA levels in SK-N-AS cells at the indicated time points. (D) UCP2 mRNA levels in SK-N-AS cells at the indicated time points. (E-H) Same as in A-D, except that cells were treated with $10 \mu \mathrm{M}$ cyclopamine for the indicated times. Values are mean \pm SEM of $6-9$ independent wells; ${ }^{*} P<0.01$ versus control.

cells (Figure 2). Of note, enough T3 is produced so that it bypasses the inactivating deiodinase (D3) present in neuronal cells. The significance of these findings is enhanced because the present experiments were performed with physiological amounts of free T4, i.e., 20 pM. Addition of T4 to the coculture system was enough to change the expression of the T3-responsive gene, ENPP2, only in the presence of the D2-expressing H4 glioma cell line. This T4dependent effect is blocked by rT3, a D2 inhibitor, and also by the highly specific $\alpha$-T3 antiserum, confirming that D2-generated T3 is a critical step in this pathway (Figure 2).

Of course, the limitations of our coculture system require one to exercise caution when generalizing the results obtained to the physiology of the brain. In order to demonstrate the paracrine loop connecting neurons and glia (Figure 7), we deconstructed the brain's architecture, purposely keeping these 2 cell types physically separated (Transwell System). The in vivo situation is likely to be more complex, since these cell types (glia and neurons) are adjacent and physically touch each other, raising the possibility of even more direct local control of TH signaling than seen in our studies. Nevertheless, given the known coexpression of D2 and D3 in the cortex, hippocampus, and hypothalamus $(14,15,23,30)$, it is likely that such a mechanism is fully active in these regions; the dependency of the LPS-mediated induction of neuronal TRH mRNA expression on tanycyte (glial) D2 activity strongly supports this hypothesis (Figure 6).

Hypoxia is an important disease signal in the brain, and in the present investigation we detected dramatic D3 induction in the rat brain after ischemia caused by MCAO (Figure 3). According to the model of $\mathrm{TH}$ action in the brain being developed here, such a D3 induction would rapidly limit the T3 footprint established in neurons, essentially rendering D3-expressing neurons relatively hypothyroid. Thus, we took advantage of the coculture system to test this hypothesis and found that, indeed, hypoxia induces D3 expression approximately 7 -fold and limits the astrocyte-dependent $\mathrm{T} 3$ footprint in neurons by at least $50 \%$ (Figure 4). Notably, the hypoxic-mimetic agent DFX pro- 


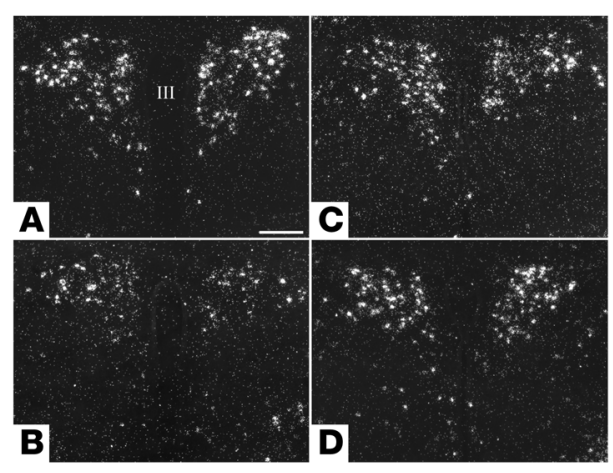

$\mathbf{F}$

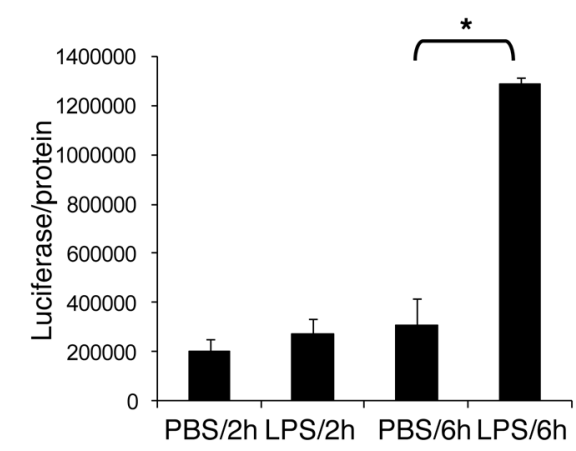

$\mathbf{E}$

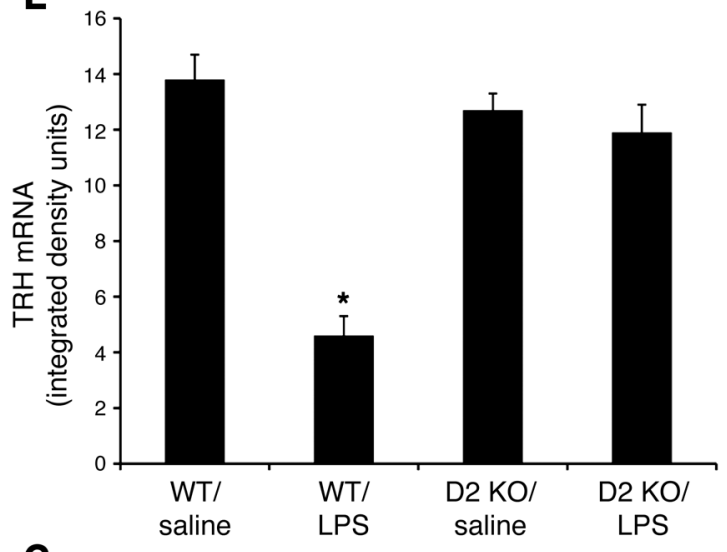

G

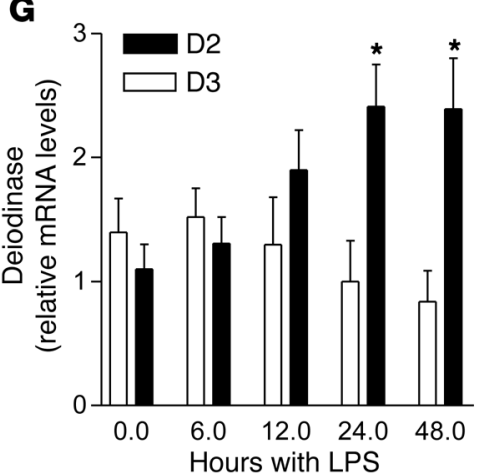

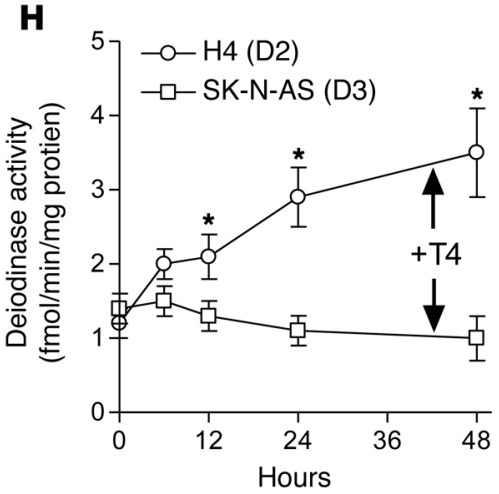
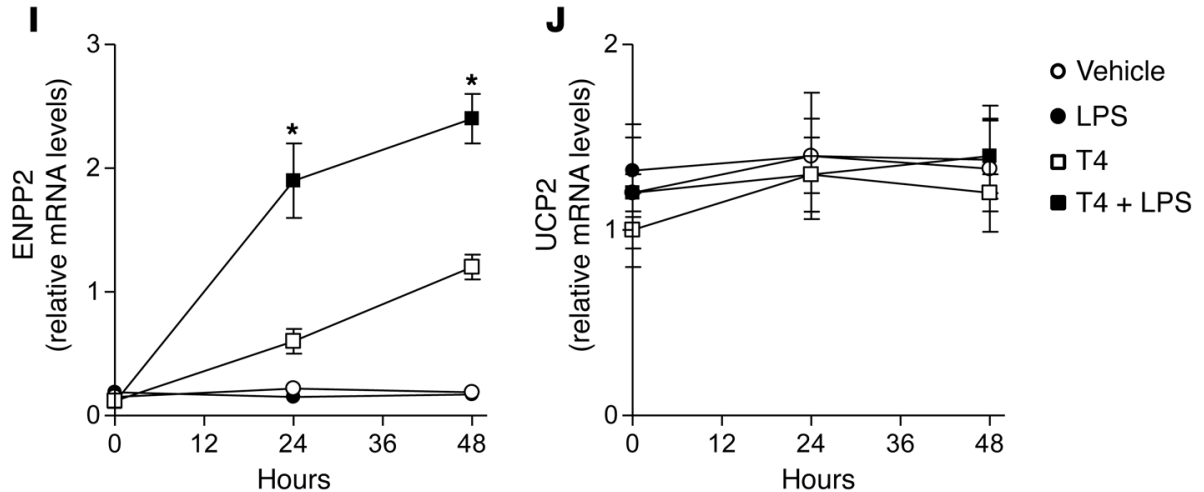

\section{Figure 6}

LPS signaling amplifies the astrocyte-mediated mRNA footprint in neuronal cells. Effect of LPS on TRH mRNA in the PVN of WT and D2-KO mice. Note apparent reduction in TRH mRNA in WT mice following the systemic administration of LPS (A-B), but absence of a response in D2-KO animals (C-D). Scale bar: $100 \mu \mathrm{m}$. III, third ventricle. (E) Quantification of the TRH mRNA hybridization signal from each of the 4 animal groups ( $n=4$ per group). (F) Luciferase activity in HEK-TLR4-MD2-ELAM cells, which have a functional LPS-NF-KB signaling via stable expression of the TLR4 receptor and an NF-кB-responsive Luciferase reporter after the addition of $1 \mu \mathrm{g} / \mathrm{ml}$ LPS (bacterial lipopolysaccharide). (G) The coculture system described in Figure 2 was exposed to LPS as in F for the indicated times in the presence of 20 pM T4 (free fraction). Cells were harvested at the indicated times and processed for deiodinase activity or quantitative RT-PCR. Shown are the time courses of D2 and D3 mRNA levels or activities (H) after addition of LPS. (I) ENPP2 mRNA levels in SK-N-AS cells at the indicated time points. (J) UCP2 mRNA levels in SK-N-AS cells at the indicated time points. Values are mean \pm SEM of $6-9$ independent wells; ${ }^{*} P<0.01$ versus control.

duced similar effects (Figure 4). These data reveal a mechanism that is intuitively adaptive in nature, given that D3-mediated hypothyroidism would decrease energy expenditure and the $\mathrm{O}_{2}$ demand of the neurons (20). From a broader perspective, such a D3 induction is likely to be part of the injury-healing process as observed in other tissues such as the myocardium (31), skeletal muscle (32), nerves (33), skin (34), and liver (35). T3 has a suppressive effect on the cyclin D1 gene (36), and thus it has been hypothesized that a decrease in TH signaling favors cell proliferation, which contributes to the healing process. Such a mechanism has been linked to cell proliferation in the chicken developing growth plate (21), the regenerating liver (35), and growth of basal cell carcinoma (22). That this also happens in the injured brain is remarkable and indicates that promoting spatial-specific hypothyroidism via induction of D3 is a default mechanism common to many injured tissues. In addition, the 


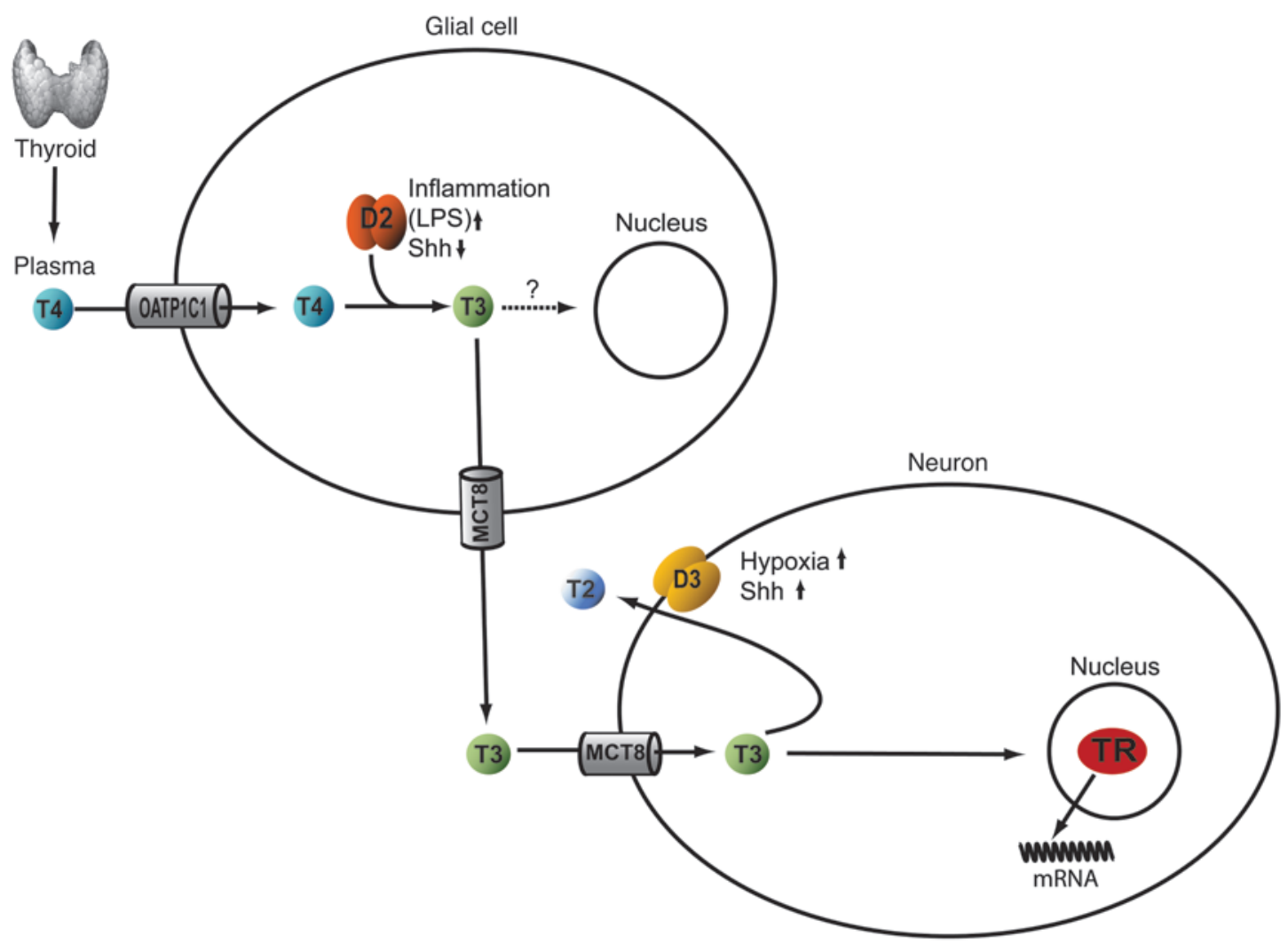

Figure 7

Proposed model of TH signaling in the brain. 3 steps characterize this paracrine mechanism: first, the prohormone T4 is activated in glial cells (astrocytes and tanycytes) via D2; next, the resultant T3 exits the glial compartment and enters adjacent neurons; and finally the T3 establishes a transcriptional footprint via binding to neuronal TRs. TH transport is via the MCT8 transporter; other TH transporters, e.g., OATP1C1, are also known to operate in the brain; LPS activates D2 transcription and Shh promotes D2 inactivation via WSB-1-mediated ubiquitination; both hypoxia and Shh activate D3 gene transcription.

possibility that D3 induction also plays a role in other types of brain injuries is very exciting, as it potentially opens new strategies for approaching patients with diverse neurological disease.

Hedgehog signaling is a known developmental player and is also induced by pathophysiological stimuli such as acute brain injury and inflammation (37). Addition of Shh in the coculture system decreased TH signaling dramatically via induction of D3 and suppression of D2 activity in astrocytes, which are known to respond to Shh signals (ref. 38 and Figure 5). Shh decreased the astrocyte-dependent T3 footprint in neurons, while cyclopamine, a Shh antagonist, caused the opposite effect (Figure 5). The observation that Shh and TH pathways may be integrated in the brain through region-specific distribution of their signaling molecules (39) should have an impact on our understanding of brain development and responsiveness to physiological and pathophysiological stimuli. In fact, during development, Shh promotes proliferation and inhibits differentiation of neural progenitors and supports dorso-ventral patterning of the CNS (40, 41). Given the critical impact of TH on brain development and function, the present investigation suggests that at least some of the Shh effects could be mediated through changes in TH signaling. Importantly, neural stem cells also exist in the adult nervous systems of all mammals and their proliferation is under Shh control (41). Here also TH signaling could be involved, explaining its role in higher cognitive functions; it has been suggested that Shh-mediated adult neurogenesis in the hippocampal dentate gyrus could play a role in memory formation (42).

The present studies also provide evidence that changes in deiodinase expression can substantially amplify the T3 footprint established in neurons via T4 deiodination in astrocytes. Specifically in the MBH, D2 is expressed in specialized glial cells, called tanycytes. It is known that systemic administration of LPS results in a rapid induction of D2 expression and activity in tanycytes, an effect linked to the suppression of TRH expression in PVN neurons observed in fasting and disease states (18). The observation that TRH mRNA in the PVN did not fall in the D2-KO mouse following the systemic administration of LPS suggests that D2 activation is a critical step in this pathway, supporting a paracrine effect of tanycyte-produced T3 via T4 deiodination on hypophysiotropic TRH neuronal regulation (Figure 6). To determine whether this was possible, we used the cocultured system and found that, indeed, exposure to LPS induced D2 expression and activity by 3- to 4-fold and more than doubled $\mathrm{TH}$ signaling to neurons in this system (Figure 6), while not affecting UCP2 mRNA levels.

Refining this paracrine model of TH action will certainly require additional studies, in particular directed to understanding the behavior of the transporters such as MCT8 in response to the factors identified as modulating deiodinase activity in the CNS. Addi- 
tional molecules and pathways capable of modulating deiodinase activity do exist, such as xenobiotic compounds (43), insulin and thiazolidinediones (44), and bile acids (45). It is exciting to speculate that these and perhaps other still-unidentified signals might affect $\mathrm{TH}$ action in the brain, with significant implications for clinical conditions such as depression and mood disorders, which are known to be affected by TH.

\section{Methods}

Reagents. T4, T3, forskolin, cyclopamine, FBS, ampicillin, gentamicin, and sodium selenite were purchased from Sigma-Aldrich. rT3 was purchased from Calbiochem. SK-N-AS cells were provided by S. Huang (Children's Hospital, Boston, Massachusetts, USA), H4 glioma cells were provided by M. LaVoie (Brigham and Women's Hospital), and HEK-TLR4-MD2-Elam cells were provided by M. Genest (Eisai Research Institute, Andover, Massachusetts, USA). The Transwell Insert was obtained from Corning Scientific. DMEM was purchased from Gibco. All reverse transcriptase materials, DNAse, RNAse out, DNTp mix, EDTA, SuperScript II, and DAPI and antibodies, anti-tubulin (mouse), Alexa Fluor 594-conjugated goat anti-mouse IgG, and Trizol were purchased from Invitrogen.

Animals. Adult male C57BL/6 WT or D2-KO mice and Sprague-Dawley rats were used as detailed in the sections describing the LPS infection and hypoxia animal models. The animals were housed under standard environmental conditions (light between 0600-1800 hours, temperature $22 \pm 1^{\circ} \mathrm{C}$, rat chow and water available ad libitum). Animals were kept and experiments were performed according to protocols approved by the Animal Care and Use Committees of Tufts University and University of Miami in compliance with NIH standards. Animal protocols followed the European Communities Council Directive of November 24, 1986 (86/609/EEC) and, when appropriate, were reviewed and approved by the Animal Welfare Committee at the Institute of Experimental Medicine, Hungarian Academy of Sciences.

LPS infection model. Experiments were performed on male C57BL/6 WT or D2-KO mice (C57BL/6 background; Jackson Laboratories) weighing between 20 and $30 \mathrm{~g}$. The D2-KO animals have been extensively characterized previously (46). LPS treatment was performed as described (18) using $250 \mu \mathrm{g} / 100 \mathrm{~g}$ of body weight i.p. injection of bacterial LPS (O127: B8; Sigma-Aldrich) in saline. Twelve or 24 hours after treatment, mice were euthanized with an overdose of pentobarbital and perfused through the ascending aorta with $4 \%$ PFA in $0.1 \mathrm{M}$ PBS-saline. Brains were postfixed for 4 hours in the same fixative, cryoprotected in 30\% sucrose, and then processed for in situ hybridization for TRH as previously described (47).

Brain bypoxia caused by surgical MCAO. Cerebral ischemia in rats was induced $(n=10)$ by a transient 60 -minute right MCAO under Nembutal anesthesia ( $60 \mathrm{mg} / \mathrm{kg}$ i.p.), as previously described $(48,49)$. Sham-operated animals $(n=10)$ underwent the same surgical procedure, but no filament was advanced to the internal carotid artery. Intraischemic neurological deficit was confirmed by detecting gait abnormalities characterized by circling or moving to the left in animals with successful MCAO. Animals showing no deficits were excluded from the study. After 60 minutes of ischemia, animals were perfused with $4 \%$ PFA solution in $0.1 \mathrm{M}$ PBS-saline.

Tissue culture and Transwell System. SK-N-AS and H4 were propagated in DMEM media with $10 \%$ FBS with $15 \mu \mathrm{g}$ gentamicin and $50 \mu \mathrm{g}$ ampicillin per liter of media. Cells were incubated overnight with $10 \%$ charcoal-stripped serum the night prior to the treatment with T4 or T3. Media for all cell types was supplemented with $10^{-7} \mathrm{M}$ sodium selenite. Cells were incubated in hypoxic or normoxic conditions in closed hypoxia chambers (Billups-Rothenberg Inc.). For the Transwell System, $1.5 \times 10^{6} \mathrm{H} 4$ cells were plated inside each Transwell insert, and $7.5 \times 10^{5} \mathrm{SK}-\mathrm{N}-\mathrm{AS}$ cells were placed a the bottom of the 6-well plate (Figure 1). Cells were plated on different 6-well plates to avoid cell mixture and placed together on the next day with $10 \%$ charcoal-stripped media. The HEK-TLR4-MD2-Elam cells stably express the TLR4-MD2 complex. These cells were used to establish concentration and timing of the cellular responsiveness to LPS (29). The cultures were maintained in DMEM media with $10 \%$ FBS supplemented with $150 \mu \mathrm{g} / \mathrm{ml}$ Zeocin, $300 \mu \mathrm{g} / \mathrm{ml} \mathrm{G} 418$, and $50 \mu \mathrm{g} / \mathrm{ml}$ hygromycin. The cells were treated in triplicate for 2 hours and 5 hours with $1 \mu \mathrm{g} / \mathrm{ml}$ LPS (026:B6; Sigma-Aldrich) or PBS as control. Mouse cortical primary astrocytes were isolated as described $(50,51)$ and kept in MEM supplemented with $10 \%$ FCS for 3-4 weeks with 1 passage. As indicated, a high-affinity rabbit polyclonal $\alpha$-T3 antiserum was added to the medium at 1:5,000 to trap released T3; when appropriate, equal amounts of normal rabbit serum was added to control wells. For immunofluorescence studies, SK-N-AS and H4 cells were plated at a lower confluence in 35-mm glass-bottom plates (MatTek Corp.), and after 24 hours, fixation was performed with $10 \%$ formalin in PBS for 30 minutes; cells were then washed in glycine buffer (100 mM glycine, $\mathrm{pH} 7.4$ ), permeabilized with $0.1 \%$ Triton X-100 in PBS for 10 minutes, and incubated overnight with primary $\alpha$-tubulin (SigmaAldrich). Secondary antibody was $\alpha$-mouse IgG labeled with Alexa Fluor 594 (goat; Molecular Probes, Invitrogen). Samples were cured for 24 hours and visualized with a Zeiss LSM META 510 (Carl Zeiss) confocal microscope.

Iodothyronine chromatography using UPLC. Cell cultures were incubated with about $250,000 \mathrm{cpm}$ of $125 \mathrm{I}-\mathrm{T} 4 / \mathrm{ml}$ or $125 \mathrm{I}-\mathrm{T} 3 / \mathrm{ml}$, totaling $2 \mathrm{ml}$ per well. Total free iodothyronine concentration was $20 \mathrm{pM}$. At the indicated times (24 hours), $100 \mu \mathrm{l}$ of medium was sampled, mixed with $100 \mu \mathrm{l}$ of $100 \%$ $\mathrm{METOH}$, and loaded to an AcQuity UPLC System (Waters). Fractions were automatically processed through a Flow Scintillation Analyzer Radiomatic 610TR (PerkinElmer) for radiometry.

$R T-P C R$. Total RNA was extracted using the Trizol method. Reverse transcriptase was performed using $3.0 \mu \mathrm{g}$ of total RNA in the SuperScript FirstStrand Synthesis System. Quantitative real-time PCR was performed using IQ SYBR Green PCR kit (Bio-Rad) using primers designed for specific genes using Primer3 software (v. 0.4.0). Expression of cyclophilin A was used as a housekeeping gene. The primer sequences used were as follows: hCycloA (forward: GGCAAATGCTGGACCCAACAC, reverse: TGCCATTCCTGGACCCAAAGC), hENPP2 (forward: ACTCCGTGAAGGCAAAGAGA, reverse: CAAGATCCGGAGATGTTGGT), hMCT8 (forward: AGCTTGATCTTATCCCCCAG, reverse: CTGCGCTACTTCACCTACGG), hMCT10 (forward: GTGCCTCATCATGGGTCTCT, reverse: ACGAAGTAACCCTGCAATGG), hOATP14 (forward: AGAGGCCAGGAAGAAAGAGG, reverse: TGGACCACACACCACAGACT), hRC3 (forward: TCAAAGTTCCCGAGGAGAGA, reverse: CTAAAAGGGCACGGACTCAG), hTR $\alpha 1$ (forward: GGCTGTGCTGCTAATGTCAA, reverse: CGGAGGTCAGTCACCTTCAT), hTR $\beta$ (forward: AGCTGAAAAATGGGGGTCTT, reverse: TCACGTGGTGTTTTCGGTAA), and hUCP2 (forward: TCTTTCCCCACCTCTTCCTT, reverse: AGGACGAAGATTCTGGCTGA). The PCR cycle conditions were as follows: 2 minutes, 30 seconds at $95^{\circ} \mathrm{C}, 30$ seconds at $95^{\circ} \mathrm{C}, 30$ seconds at $60^{\circ} \mathrm{C}$, and 45 seconds at $72^{\circ} \mathrm{C}$ for 50 cycles followed by the melting curve protocol to verify the specificity of amplicon generation. Gene expression was determined by generation of a standard curve as described (52). cDNA synthesis for semiquantitative RT-PCR on 2 separate cultures of cortical astrocytes was performed using standard procedures. In the minus reverse transcription controls, reverse transcriptase was replaced by water. The cDNA was amplified by Taq polymerase for 35 cycles using intron-spanning primers. In negative controls, Taq was replaced by water.

D3 immunohistochemistry. Brains were post-fixed in 4\% PFA overnight then infiltrated with $20 \%$ sucrose solution until they sunk. Prior to cutting, brains were labeled by micropunches for subsequent identification. $25-\mu \mathrm{m}$-thick sections were cut on a freezing microtome. Every sixth section per brain from operated (MCAO) and sham-operated animals was processed in the same staining jars according to immunocytochemical procedures described earlier (53). Sections were incubated in $1 \mu \mathrm{g} / \mathrm{ml} \mathrm{rabbit}$ polyclonal anti-rat D3 anti- 
serum (NBP1-05767B raised against rat protein residues within aa 250-300; Novus Biologicals) for 36 hours at $4^{\circ} \mathrm{C}$, followed by biotinylated donkey anti-rabbit secondary antibody (1:1,000; Jackson Immunoresearch Laboratories) for 2 hours, and finally, peroxidase-conjugated avidin biotin complex (ABC, 1:3,000; Vector Laboratories) for 1.5 hours. Tissues were rinsed in PBS between immunohistochemical steps. The immunoreactive sites were visualized with $2.5 \%$ 3,3-diaminobenzidine and $0.15 \%$ nickel ammonium sulfate dissolved in TRIS buffer, $\mathrm{pH}$ 7.6. In some sections, the immunoreaction product was silver-gold intensified (53). Sections were then mounted, dehydrated, cleared in xylene, and coverslipped with DPX (Fluka).

The staining pattern obtained by the NBP1-05767B antiserum was comparable to that obtained with an antiserum (NB110-96414 Novus Biologicals) recognizing a different epitope of the D3 protein within aa 1-100 (not shown) and to in situ hybridization signal for the rat D3 mRNA (23). When increasing dilution of the antibody was used, the immunohistochemical signal decreased in each D3-positive site in the forebrain. No signal was detected when the primary antibody (NBP1-05767B) was omitted from the immunohistochemical procedure or the working dilution of the antiserum was preincubated with its blocking peptide (NBP1-0767PEP; Novus Biologicals).

Deiodination assays. Analysis was performed using cell sonicates prepared using $0.1 \mathrm{M}$ phosphate and $1 \mathrm{mM}$ EDTA at $\mathrm{pH} 6.9$ with $10 \mathrm{mM}$ dithiothreitol and $0.25 \mathrm{M}$ sucrose. D1, D2, and D3 assays were performed as previously described (20).
Statistics. Comparisons were performed by 2-tailed Student's $t$ test, and multiple comparisons were by ANOVA followed by Student-NeumanKeuls test. $P<0.05$ was used to reject the null hypothesis.

\section{Acknowledgments}

We thank B. Kim for helping in the writing of this manuscript, M. Lavoie for the H4 cell line, Steve Huang for the SK-N-AS cell line, Melinda Genest for the HEK-TLR4-MD2-Elam cells, and Z. Környei for her help with primary astrocyte cultures. The technical assistance of V. Hársfalvi is gratefully appreciated. This work was supported by NIH grants DK77086 and DK37021, Fundacao de Amparo a Pesquisa do Estado de Sao Paulo (FAPESP) grants 05/55825-8 and 05/55826-4, Hungarian Scientific Research Fund grant OTKA K81226, and the János Bolyai Research Scholarship of the Hungarian Academy of Sciences.

Received for publication December 8, 2009, and accepted in revised form March 17, 2010.

Address correspondence to: Antonio C. Bianco, University of Miami Miller School of Medicine, 1400 N.W. 10th Avenue, Suite 816, Miami, Florida 33136, USA. Phone: 305.243.5631; Fax: 305.243.7268; E-mail: abianco@med.miami.edu.
1. Oppenheimer JH, Schwartz HL. Molecular basis of thyroid hormone-dependent brain development. Endocr Rev. 1997;18(4):462-475.

2. Bernal J, Guadano-Ferraz A, Morte B. Perspectives in the study of thyroid hormone action on brain development and function. Thyroid. 2003;13(11):1005-1012.

3. Williams GR. Neurodevelopmental and neurophysiological actions of thyroid hormone. J Neuroendocrinol. 2008;20(6):784-794.

4. Crantz FR, Silva JE, Larsen PR. Analysis of the sources and quantity of 3,5,3'-triiodothyronine specifically bound to nuclear receptors in rat cerebral cortex and cerebellum. Endocrinology. 1982;110(2):367-375

5. Galton VA, et al. Thyroid hormone homeostasis and action in the type 2 deiodinase-deficient rodent brain during development. Endocrinology. 2007;148(7):3080-3088.

6. Fliers E, Alkemade A, Wiersinga WM, Swaab DF. Hypothalamic thyroid hormone feedback in health and disease. Prog Brain Res. 2006;153:189-207.

7. Yoshimura T, et al. Light-induced hormone conversion of $\mathrm{T} 4$ to $\mathrm{T} 3$ regulates photoperiodic response of gonads in birds. Nature. 2003;426(6963):178-181.

8. Desouza LA, Ladiwala U, Daniel SM, Agashe S, Vaidya RA, Vaidya VA. Thyroid hormone regulates hippocampal neurogenesis in the adult rat brain. Mol Cell Neurosci. 2005;29(3):414-426.

9 . Bernal J. Thyroid hormone receptors in brain development and function. Nat Clin Pract Endocrinol Metab. 2007;3(3):249-259.

10. Visser WE, Friesema EC, Jansen J, Visser TJ. Thyroid hormone transport by monocarboxylate transporters. Best Pract Res Clin Endocrinol Metab. 2007;21(2):223-236.

11. Nillni EA. Regulation of the hypothalamic Thyrotropin Releasing Hormone (TRH) neuron by neuronal and peripheral inputs [published online ahead of print January 13, 2010]. Front Neuroendocrinol. doi:10.1016/j.yfrne.2010.01.001.

12. Friesema EC, et al. Association between mutations in a thyroid hormone transporter and severe X-linked psychomotor retardation. Lancet. 2004;364(9443):1435-1437.

13. Dumitrescu AM, Liao XH, Best TB, Brockmann K, Refetoff S. A novel syndrome combining thyroid and neurological abnormalities is associated with mutations in a monocarboxylate transporter gene. Am J Hum Genet. 2004;74(1):168-175.

14. Guadano-Ferraz A, Obregon MJ, St Germain DL, Bernal J. The type 2 iodothyronine deiodinase is expressed primarily in glial cells in the neonatal rat brain. Proc Natl Acad Sci U S A. 1997;94(19):10391-10396.

15. Tu HM, et al. Regional distribution of type 2 thyroxine deiodinase messenger ribonucleic acid in rat hypothalamus and pituitary and its regulation by thyroid hormone. Endocrinology. 1997;138(8):3359-3368.

16. Fekete C, Lechan RM. Negative feedback regulation of hypophysiotropic thyrotropin-releasing hormone (TRH) synthesizing neurons: role of neuronal afferents and type 2 deiodinase. Front Neuroendocrinol. 2007;28(2-3):97-114.

17. Diano S, Naftolin F, Goglia F, Horvath TL. Fastinginduced increase in type II iodothyronine deiodinase activity and messenger ribonucleic acid levels is not reversed by thyroxine in the rat hypothalamus. Endocrinology. 1998;139(6):2879-2884.

18. Fekete C, et al. Lipopolysaccharide induces type 2 iodothyronine deiodinase in the mediobasal hypothalamus: implications for the nonthyroidal illness syndrome. Endocrinology. 2004;145(4):1649-1655.

19. Boelen A, Kwakkel J, Thijssen-Timmer DC, Alkemade A, Fliers E, Wiersinga WM. Simultaneous changes in central and peripheral components of the hypothalamus-pituitary-thyroid axis in lipopolysaccharide-induced acute illness in mice. J Endocrinol. 2004;182(2):315-323.

20. Simonides WS, et al. Hypoxia-inducible factor induces local thyroid hormone inactivation during hypoxic-ischemic disease in rats. J Clin Invest. 2008;118(3):975-983.

21. Dentice M, et al. The Hedgehog-inducible ubiquitin ligase subunit WSB-1 modulates thyroid hormone activation and PTHrP secretion in the developing growth plate. Nat Cell Biol. 2005;7(7):698-705.

22. Dentice M, et al. Sonic hedgehog-induced type 3 deiodinase blocks thyroid hormone action enhancing proliferation of normal and malignant keratinocytes. Proc Natl Acad Sci U S A. 2007;104(36):14466-14471.

23. Tu HM, Legradi G, Bartha T, Salvatore D, Lechan RM, Larsen PR. Regional expression of the type 3 iodothyronine deiodinase messenger ribonucleic acid in the rat central nervous system and its regulation by thyroid hormone. Endocrinology. 1999;140(2):784-790.

24. Lee JC, Mayer-Proschel M, Rao MS. Gliogenesis in the central nervous system. Glia. 2000;30(2):105-121.

25. Christoffolete MA, et al. Atypical expression of type 2 iodothyronine deiodinase in thyrotrophs explains the thyroxine-mediated pituitary thyrotropin feedback mechanism. Endocrinology. 2006;147(4):1735-1743.

26. Luiza Maia A, Kim BW, Huang SA, Harney JW, Larsen PR. Type 2 iodothyronine deiodinase is the major source of plasma T(3) in euthyroid humans. J Clin Invest. 2005;115(9):2524-2533.

27. St Germain DL. The effects and interactions of substrates, inhibitors, and the cellular thiol-disulfide balance on the regulation of type II iodothyronine 5 'deiodinase. Endocrinology. 1988;122(5):1860-1868.

28. Sims JR, et al. Sonic Hedgehog regulates ischemia/ hypoxia-induced neural progenitor proliferation. Stroke. 2009;40(11):3618-3626.

29. Yang H, Young DW, Gusovsky F, Chow JC. Cellular events mediated by lipopolysaccharide-stimulated toll-like receptor 4. MD-2 is required for activation of mitogen-activated protein kinases and Elk-1. J Biol Chem. 2000;275(27):20861-20866.

30. Escamez MJ, Guadano-Ferraz A, Cuadrado A, Bernal J. Type 3 iodothyronine deiodinase is selectively expressed in areas related to sexual differentiation in the newborn rat brain. Endocrinology. 1999;140(11):5443-5446.

31. Olivares EL, et al. Thyroid function disturbance and type 3 iodothyronine deiodinase induction after myocardial infarction in rats a time course study. Endocrinology. 2007;148(10):4786-4792.

32. Boelen A, et al. Induction of type 3 deiodinase activity in inflammatory cells of mice with chronic local inflammation. Endocrinology. 2005;146(12):5128-5134.

33. Li WW, Le Goascogne C, Ramauge M, Schumacher M, Pierre M, Courtin F. Induction of type 3 iodothyronine deiodinase by nerve injury in the rat peripheral nervous system. Endocrinology. 2001;142(12):5190-5197.

34. Santini F, et al. Role for inner ring deiodination preventing transcutaneous passage of thyroxine. 
J Clin Endocrinol Metab. 2003;88(6):2825-2830.

35. Kester MH, et al. Large induction of type III deiodinase expression after partial hepatectomy in the regenerating mouse and rat liver. Endocrinology. 2009;150(1):540-545.

36. Garcia-Silva S, Perez-Juste G, Aranda A. Cell cycle control by the thyroid hormone in neuroblastoma cells. Toxicology. 2002;181-182:179-182.

37. Amankulor NM, Hambardzumyan D, Pyonteck SM, Becher OJ, Joyce JA, Holland EC. Sonic hedgehog pathway activation is induced by acute brain injury and regulated by injury-related inflammation. J Neurosci. 2009;29(33):10299-10308.

38. Wallace VA, Raff MC. A role for Sonic hedgehog in axon-to-astrocyte signalling in the rodent optic nerve. Development. 1999;126(13):2901-2909.

39. Fekete C, et al. Expression patterns of WSB-1 and USP-33 underlie cell-specific posttranslational control of type 2 deiodinase in the rat brain. Endocrinology. 2007;148(10):4865-4874.

40. Rowitch DH, B SJ, Lee SM, Flax JD, Snyder EY, McMahon AP. Sonic hedgehog regulates proliferation and inhibits differentiation of CNS precursor cells. J Neurosci. 1999;19(20):8954-8965.

41. Lai K, Kaspar BK, Gage FH, Schaffer DV. Sonic hedgehog regulates adult neural progenitor proliferation in vitro and in vivo. Nat Neurosci.
2003;6(1):21-27.

42. Whitfield JF, Chakravarthy BR. The neuronal primary cilium: driver of neurogenesis and memory formation in the hippocampal dentate gyrus? Cell Signal. 2009;21(9):1351-1355.

43. da-Silva WS, et al. The small polyphenolic molecule kaempferol increases cellular energy expenditure and thyroid hormone activation. Diabetes. 2007;56(3):767-776.

44. Grozovsky R, et al. Type 2 deiodinase expression is induced by peroxisomal proliferator-activated receptor-gamma agonists in skeletal myocytes. Endocrinology. 2009;150(4):1976-1983.

45. Watanabe $M$, et al. Bile acids induce energy expenditure by promoting intracellular thyroid hormone activation. Nature. 2006;439(7075):484-489.

46. Schneider MJ, Fiering SN, Pallud SE, Parlow AF, St Germain DL, Galton VA. Targeted disruption of the type 2 selenodeiodinase gene (DIO2) results in a phenotype of pituitary resistance to T4. Mol Endocrinol. 2001;15(12):2137-2148.

47. Fekete C, Sarkar S, Rand WM, Harney JW, Emerson $\mathrm{CH}$, Bianco AC, Lechan RM. Agouti-related protein (AGRP) has a central inhibitory action on the hypothalamic-pituitary-thyroid (HPT) axis; comparisons between the effect of AGRP and neuropeptide $\mathrm{Y}$ on energy homeostasis and the HPT axis. Endocrinology. 2002;143(10):3846-3853.

48. Longa EZ, Weinstein PR, Carlson S, Cummins R. Reversible middle cerebral artery occlusion without craniectomy in rats. Stroke. 1989;20(1):84-91.

49. Matucz E, et al. Reduction of cerebral infarct size by non-competitive AMPA antagonists in rats subjected to permanent and transient focal ischemia. Brain Res. 2004;1019(1-2):210-216.

50. Gereben B, Leuhuber K, Rausch WD, Galfi P, Jancsik V, Rudas P. Inverse hierarchy of vimentin epitope expression in primary cultures of chicken and rat astrocytes: a double-immunofluorescence study. Neurobiology (Bp). 1998;6(2):141-150.

51. Kornyei Z, Szlavik V, Szabo B, Gocza E, Czirok A, Madarasz E. Humoral and contact interactions in astroglia/stem cell co-cultures in the course of gliainduced neurogenesis. Glia. 2005;49(3):430-444.

52. Curcio-Morelli C, et al. Deubiquitination of type 2 iodothyronine deiodinase by von Hippel-Lindau protein-interacting deubiquitinating enzymes regulates thyroid hormone activation. J Clin Invest. 2003;112(2):189-196.

53. Kallo I, Butler JA, Barkovics-Kallo M, Goubillon ML, Coen CW. Oestrogen receptor beta-immunoreactivity in gonadotropin releasing hormoneexpressing neurones: regulation by oestrogen. J Neuroendocrinol. 2001;13(9):741-748. 